\title{
Central motor conduction in multiple sclerosis: evaluation of abnormalities revealed by transcutaneous magnetic stimulation of the brain
}

\author{
D A INGRAM, A J THOMPSON, M SWASH \\ From the Departments of Clinical Neurophysiology and Neurology, The London Hospital, London, UK
}

SUMMARY Magnetic stimulation of the brain and spinal column was used to assess conduction in the descending central motor pathways controlling arm and leg muscles of 20 patients with multiple sclerosis, and 10 normal subjects. The multiple sclerosis patients had relapsing and remitting disease but all were ambulant and in stable clinical remission. Increased central motor conduction times (CMCTs), up to three times normal, were frequently encountered in multiple sclerosis patients and in leg muscles these correlated closely with clinical signs of upper motor neuron disturbance; in the upper limb muscles a higher proportion of subclinical lesions was present. Weak muscles were almost invariably associated with abnormal central conduction but increased CMCTs were also found for 52 of the 104 muscles with normal strength. CMCTs for lower limb muscles were directly related ( $\mathrm{p}<0.005)$ to functional motor disability (Kurtzke and Ambulatory Index Scales). No patient developed clinical evidence of relapse during follow-up of at least 8 months. Magnetic brain stimulation is easy to perform, painless, and safe, and provides clinically relevant information in the diagnosis and monitoring of multiple sclerosis patients.

Direct measurements of conduction times in the descending central motor tracts of awake subjects can be made by applying single transcutaneous electrical stimuli over the brain and spinal column and recording responses from limb muscles. ${ }^{1}$ This permits selective assessment of central motor tracts without the need for averaging multiple responses as required for sensory evoked responses. Using this technique, impaired conduction has been demonstrated in subcortical, brainstem and spinal segments of the neuraxis in patients with multiple sclerosis, ${ }^{2-4}$ radiation myelopathy ${ }^{3}$ and motor neuron disease. ${ }^{5}$ However, electrical stimuli are greatly attenuated by passage through bone and other tissues and the threshold for stimulation tends to rise in both primary demyelinating and degenerative disorders. For these reasons the stimuli required to excite motor pathways in patients with these diseases are often uncomfortable and may be ineffective ${ }^{25}$ particularly for recordings made from leg muscles. ${ }^{5}$

An alternative stimulation technique has recently Address for reprint requests: Dr D A Ingram, The London Hospital,
Whitechapel, London E1 1 BB, UK.

Received 19 December 1986 and in revised form 20 October 1987. Accepted 26 October 1987 been described which achieves depolarisation of central nervous tissue in the brain by pulsed electromagnetic stimulation. ${ }^{6}$ This form of stimulation is not attenuated by passage through body tissues or clothing and is virtually painfree. Repeated stimuli, which may be required to study small abnormal responses, are thus well tolerated. We have used this new technique to evaluate the usefulness of central motor conduction measurements in patients with clinically definite multiple sclerosis in remission. The electrophysiological findings have been compared with signs of weakness and upper motor neuron involvement and with clinical assessments of functional motor disability.

\section{Patients}

Twenty patients, aged between 24 and 56 (mean 38) years with clinically definite multiple sclerosis ${ }^{7}$ were studied. All had clinical evidence of relapsing and remitting disease but had been in stable clinical remission for at least one month prior to the study. ${ }^{8}$ The Kurtzke Disability Status Scale ${ }^{9}$ and the Ambulatory Index ${ }^{10}$ were used as measures of disability. The clinical details are summarised in table 1 . All patients were ambulant (Kurtzke Scale $\leqslant 6$ ). In seven 
Table 1 Patient details and central motor conduction times (CMCT's) for individual muscles.

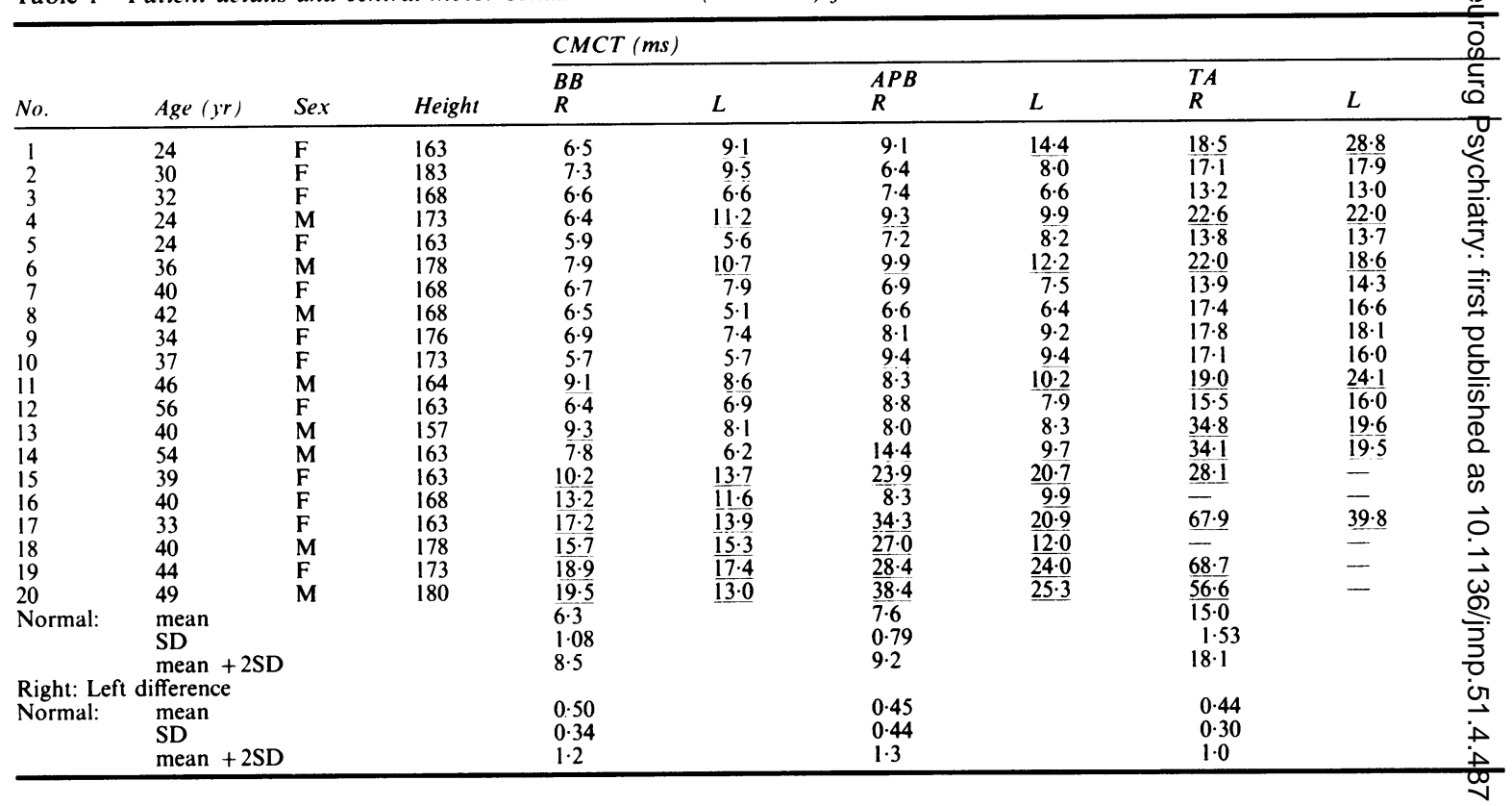

(a)
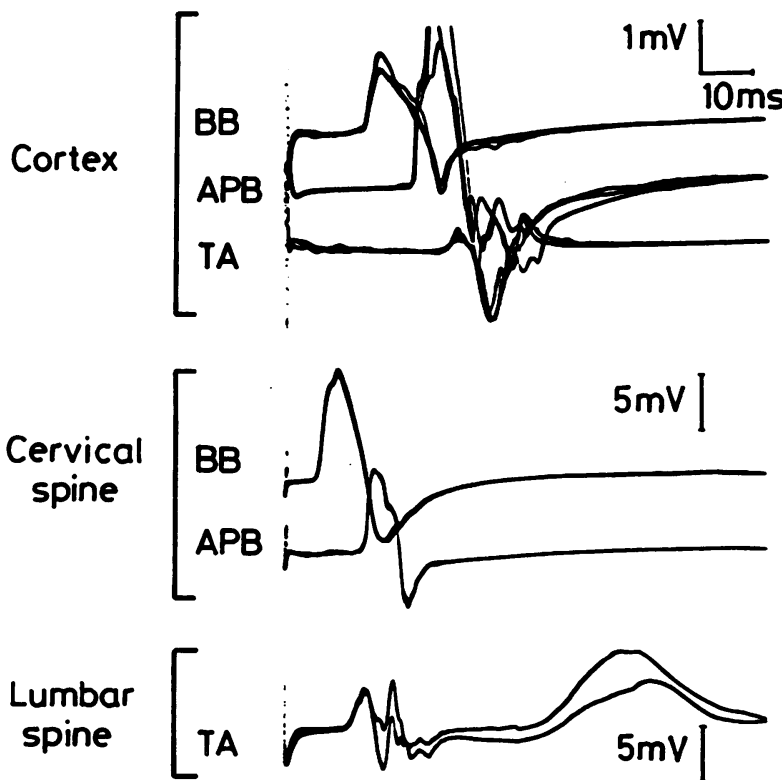

TA
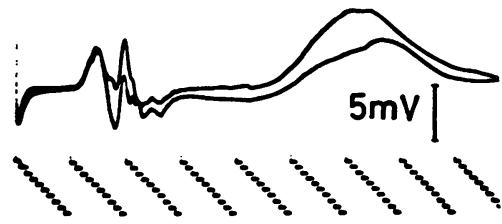

(b)

욱

$\vec{\nabla}$

응을.
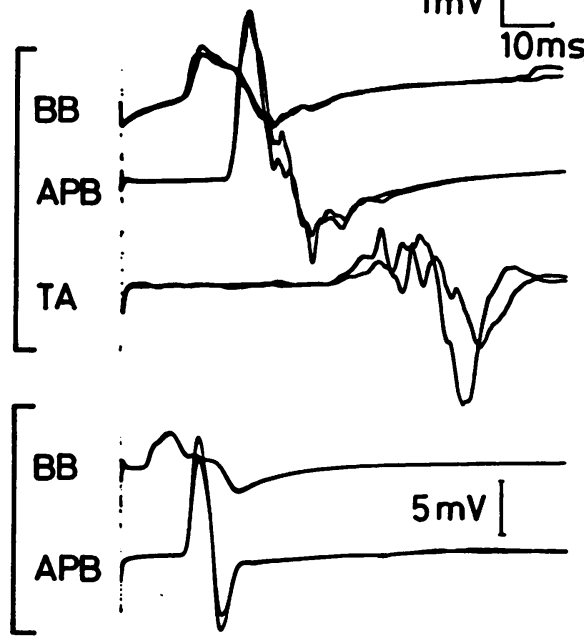

TA
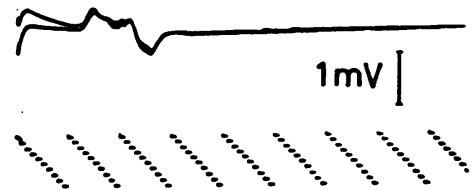

Fig 1 Consecutive muscle responses superimposed after stimulation at cortex, cervical spine and lumbar spine, recorded from biceps brachii (BB), abductor pollicis brevis (APB) and tibialis anterior $(T A)$. (a) Normal subject. (b) Patient with multiple sclerosis (case 1). The latency from cortex to TA and the CMCT for this muscle are both increased (see tables 1 and 2). Note the abnormal dispersion and increased variability of the TA muscle response to consecutive stimuli. 


\begin{tabular}{|c|c|c|c|c|c|c|c|c|c|c|c|c|c|c|c|}
\hline \multicolumn{6}{|c|}{ Strength (MRC scale) } & \multicolumn{7}{|c|}{ Reflexes } & \multirow[b]{2}{*}{ Kurtzke scale } & \multirow[b]{2}{*}{ Ambulatory index } & \multirow[b]{2}{*}{$\begin{array}{l}\text { Duration of } \\
\text { illness }(y r)\end{array}$} \\
\hline $\begin{array}{l}B B \\
R\end{array}$ & $L$ & $\begin{array}{l}A P B \\
R\end{array}$ & $L$ & $\begin{array}{l}T A \\
R \\
\end{array}$ & $L$ & $\begin{array}{l}B J \\
R \\
\end{array}$ & $L$ & $\begin{array}{l}K J \\
R \\
\end{array}$ & $L$ & $\begin{array}{l}A J \\
R\end{array}$ & $L$ & $\begin{array}{l}\text { Plantar } \\
R \quad L \\
\end{array}$ & & & \\
\hline $\begin{array}{l}\mathbf{N} \\
\mathbf{N} \\
\mathbf{N} \\
\mathbf{N} \\
\mathbf{N} \\
\mathbf{N} \\
\mathbf{N} \\
\mathbf{N} \\
\mathbf{N} \\
\mathbf{N} \\
\mathbf{N} \\
\mathbf{N} \\
\mathbf{N} \\
\mathbf{N} \\
\mathbf{N} \\
\mathbf{N} \\
\mathbf{N} \\
\mathbf{N} \\
\mathbf{N}\end{array}$ & $\begin{array}{l}\mathbf{N} \\
\mathbf{N} \\
\mathbf{N} \\
\mathbf{N} \\
\mathbf{N} \\
\mathbf{N} \\
\mathbf{N} \\
\mathbf{N} \\
\mathbf{N} \\
\mathbf{N} \\
\mathbf{N} \\
\mathbf{N} \\
\mathbf{N} \\
\mathbf{N} \\
\mathbf{N} \\
\mathbf{N} \\
\mathbf{N} \\
\mathbf{N} \\
\mathbf{N} \\
\mathbf{N}\end{array}$ & $\begin{array}{l}\mathbf{N} \\
\mathbf{N} \\
\mathbf{N} \\
\mathbf{N} \\
\mathbf{N} \\
\mathbf{N} \\
\mathbf{N} \\
\mathbf{N} \\
\mathbf{N} \\
\mathbf{N} \\
\mathbf{N} \\
4 \\
\mathbf{N} \\
\mathbf{N} \\
\mathbf{N} \\
\mathbf{N} \\
\mathbf{N} \\
\mathbf{N} \\
\mathbf{N} \\
\mathbf{N}\end{array}$ & $\begin{array}{l}N \\
N \\
N \\
N \\
N \\
N \\
N \\
N \\
N \\
N \\
N \\
N \\
N \\
N \\
N \\
N \\
N \\
N \\
4 \\
N\end{array}$ & $\begin{array}{l}\mathbf{N} \\
\mathbf{N} \\
\mathrm{N} \\
\mathrm{N} \\
\mathrm{N} \\
\mathrm{N} \\
\mathrm{N} \\
\mathrm{N} \\
\mathrm{N} \\
\mathrm{N} \\
\mathrm{N} \\
4 \\
\mathrm{~N} \\
4 \\
3 \\
3 \\
4 \\
3 \\
4 \\
4\end{array}$ & $\begin{array}{l}N \\
N \\
N \\
N \\
N \\
N \\
N \\
N \\
N \\
4 \\
N \\
N \\
N \\
N \\
4 \\
3 \\
4 \\
N \\
3 \\
4\end{array}$ & $\begin{array}{l}\mathbf{N} \\
\mathbf{N} \\
\mathbf{N} \\
3 \\
\mathbf{N} \\
\mathbf{N} \\
\mathbf{N} \\
\mathbf{N} \\
\mathbf{N} \\
\mathbf{N} \\
3 \\
\mathbf{N} \\
\mathbf{N} \\
3 \\
\mathbf{N} \\
3 \\
\mathbf{N} \\
\mathbf{N} \\
3 \\
3\end{array}$ & $\begin{array}{l}\mathbf{N} \\
\mathbf{N} \\
\mathbf{N} \\
3 \\
\mathbf{N} \\
\mathbf{N} \\
\mathbf{N} \\
\mathbf{N} \\
\mathbf{N} \\
\mathbf{N} \\
3 \\
\mathbf{N} \\
\mathbf{N} \\
3 \\
\mathbf{N} \\
3 \\
\mathbf{N} \\
\mathbf{N} \\
3 \\
3\end{array}$ & $\begin{array}{l}3 \\
3 \\
\mathbf{N} \\
3 \\
3 \\
3 \\
3 \\
3 \\
3 \\
3 \\
3 \\
\mathrm{~N} \\
3 \\
3 \\
3 \\
3 \\
3 \\
3 \\
3 \\
4\end{array}$ & $\begin{array}{l}3 \\
3 \\
N \\
3 \\
3 \\
3 \\
3 \\
3 \\
3 \\
3 \\
3 \\
N \\
3 \\
3 \\
3 \\
3 \\
3 \\
3 \\
3 \\
4\end{array}$ & $\begin{array}{l}3 \\
N \\
N \\
3 \\
N \\
3 \\
N \\
N \\
N \\
N \\
3 \\
N \\
3 \\
4 \\
N \\
3 \\
3 \\
4 \\
4 \\
4\end{array}$ & $\begin{array}{l}3 \\
N \\
N \\
3 \\
N \\
3 \\
N \\
N \\
N \\
N \\
3 \\
N \\
3 \\
4 \\
N \\
3 \\
3 \\
4 \\
4 \\
4\end{array}$ & $\begin{array}{l}\uparrow \\
\uparrow\end{array}$ & $\begin{array}{l}1 \\
1 \\
1 \\
2 \\
2 \\
2 \\
2 \\
2 \\
3 \\
3 \\
3 \\
3 \\
4 \\
4 \\
5 \\
5 \\
6 \\
6 \\
6 \\
6\end{array}$ & $\begin{array}{l}0 \\
0 \\
0 \\
2 \\
1 \\
1 \\
2 \\
0 \\
3 \\
4 \\
2 \\
2 \\
4 \\
3 \\
6 \\
6 \\
6 \\
6 \\
6 \\
6\end{array}$ & $\begin{array}{r}3 \\
2 \\
1 \\
7 \\
8 \\
19 \\
3 \\
5 \\
1 \\
7 \\
16 \\
11 \\
15 \\
19 \\
5 \\
10 \\
4 \\
12 \\
33 \\
13\end{array}$ \\
\hline
\end{tabular}

KEY: $\mathrm{F}=$ Female, $\mathrm{M}=$ Male, BB = Biceps brachii, APB = Thenar eminence, TA = Tibialis anterior, - absent response. Strength: $\mathbf{N}=$ Normal $(\mathrm{MRC}$ Grade 5)

Reflexes: BJ = Biceps jerk, $\mathrm{KJ}=$ Knee jerk, $\mathrm{AJ}=$ Ankle jerk; $\mathrm{N}=$ Normal, $3=$ increased, $4=$ increased with clonus. Plantar responses: $\uparrow=$ extensor, $\downarrow=$ flexor

Abnormal CMCTs (> mean + 2SD) underlined

patients (Cases 2, 3, 5, 7, 8, 9, 12) the plantar responses were flexor at the time of the study, but in case 12 there was mild weakness of corticospinal distribution in the right arm and leg. Cases 7 and 9 had clinical evidence of mild upper motor neuron involvement during a previous relapse.

In all patients the diagnosis had been established by clinical criteria ${ }^{7}$ including the results of CSF examination, CT scanning, visual evoked potential studies, myelography and magnetic resonance imaging (MRI) when appropriate. Patients with a history of blackouts, cardiac disease or implantation of metal clips, protheses or pacemakers were excluded from the study.

Ten normal volunteers, aged between 24 and 53 (mean 37) years served as controls. All patients and volunteers gave their informed consent to the investigation, which was approved by the Ethical Committee of The London Hospital.

\section{Methods}

The stimulating equipment used for this study has been described previously ${ }^{6}$ and consists of a large capacitor bank which can be discharged via thyristors through a circular copper coil of $10 \mathrm{~cm}$ mean diameter. The resultant magnetic field induces a small current with subsequent depolarisation of nervous tissue. Transcutaneous magnetic stimulation of the brain was carried out by placing the coil over the vertex of the skull. This position was found to be optimal for excitation of upper limb muscles in most subjects. For leg muscles the optimal site was usually slightly anterior to this position. In many cases simultaneous surface EMG recordings could be made from the biceps brachii (BB), thenar eminence (APB) and tibialis anterior (TA) muscles contralateral to the stimulated cortex (fig 1).

By inverting the coil, the direction of current flow could be reversed and this permitted preferential stimulation of the opposite cortex. During stimulation, subjects were asked to make a slight sustained voluntary contraction of at least $5 \%$ maximal isometric tension of the test muscle which was monitored by the surface EMG signal. ${ }^{11}$ Facilitation $^{1}$ was associated with increased amplitude and decreased latency of the muscle responses. The stimulus strength was adjusted to obtain the shortest latency. However, even under these conditions some variation in amplitude and latency, up to 2 $\mathrm{ms}$, was observed. At least six recordings were therefore made from each muscle for each stimulation site to ensure the consistency of the shortest motor latency. The variability in amplitude of the muscle response reached $400 \%$ in some subjects and precluded reliable study of this variable.

Conduction times in the lower motor neuron component 
Table 2 Latencies (ms) to individual muscles for different stimulation sites in multiple sclerosis patients

\begin{tabular}{|c|c|c|c|c|c|c|c|c|c|c|c|c|}
\hline \multirow[b]{3}{*}{ Pt. No. } & \multicolumn{6}{|c|}{ Cortex } & \multicolumn{4}{|c|}{ Cervical } & \multicolumn{2}{|c|}{ Lumbar } \\
\hline & \multicolumn{2}{|l|}{$B B$} & \multicolumn{2}{|l|}{$A P B$} & \multicolumn{2}{|l|}{$T A$} & \multicolumn{2}{|l|}{$B B$} & \multicolumn{2}{|l|}{$A P B$} & \multicolumn{2}{|l|}{$T A$} \\
\hline & $R$ & $L$ & $R$ & $L$ & $R$ & $L$ & $R$ & $L$ & $R$ & $L$ & $R$ & $L$ \\
\hline 1 & $11 \cdot 4$ & $14 \cdot 1$ & $21 \cdot 0$ & $26 \cdot 2$ & $30 \cdot 5$ & $40 \cdot 8$ & 4.9 & $5 \cdot 0$ & 11.9 & 11.8 & $12 \cdot 0$ & $12 \cdot 0$ \\
\hline 2 & $12 \cdot 3$ & 15.0 & $21 \cdot 0$ & $22 \cdot 7$ & $31 \cdot 5$ & $32 \cdot 5$ & 5.0 & $5 \cdot 5$ & 14.6 & $14 \cdot 7$ & $14 \cdot 4$ & $14 \cdot 6$ \\
\hline 3 & $12 \cdot 0$ & 11.9 & $21 \cdot 7$ & $20 \cdot 8$ & $27 \cdot 7$ & $27 \cdot 3$ & 5.4 & $5 \cdot 3$ & 14.3 & $14 \cdot 2$ & 14.5 & $14 \cdot 3$ \\
\hline 4 & $12 \cdot 2$ & 16.5 & $24 \cdot 0$ & $24 \cdot 7$ & $36 \cdot 7$ & $35 \cdot 3$ & 5.8 & $5 \cdot 3$ & 14.7 & 14.8 & $14 \cdot 1$ & 13.3 \\
\hline 5 & $10 \cdot 8$ & $10 \cdot 5$ & 19.8 & $20 \cdot 8$ & 26.7 & $26 \cdot 7$ & 4.9 & 4.9 & 12.6 & $12 \cdot 6$ & 12.9 & 13.0 \\
\hline 6 & 13.0 & 15.9 & $23 \cdot 1$ & $25 \cdot 8$ & $36 \cdot 2$ & 32.9 & $5 \cdot 1$ & $5 \cdot 2$ & $13 \cdot 2$ & 13.6 & $14 \cdot 2$ & $14 \cdot 3$ \\
\hline 7 & 12.0 & $13 \cdot 5$ & $20 \cdot 9$ & $21 \cdot 9$ & 28.9 & 29.0 & $5 \cdot 3$ & 5.6 & 14.0 & 14.4 & 15.0 & 14.7 \\
\hline 8 & $12 \cdot 4$ & 10.4 & 19.8 & $19 \cdot 3$ & $30 \cdot 3$ & $29 \cdot 3$ & 5.9 & $\begin{array}{l}5.0 \\
5.3\end{array}$ & $13 \cdot 2$ & 12.9 & 12.9 & 12.7 \\
\hline 9 & $12 \cdot 0$ & $12 \cdot 6$ & $21 \cdot 0$ & $22 \cdot 0$ & $30 \cdot 0$ & $31 \cdot 3$ & $5 \cdot 1$ & $\begin{array}{l}5.3 \\
5 \cdot 2\end{array}$ & 12.9 & $12 \cdot 8$ & $12 \cdot 2$ & $13 \cdot 2$ \\
\hline 10 & 10.9 & 11.0 & $21 \cdot 6$ & $22 \cdot 1$ & $30 \cdot 0$ & $29 \cdot 5$ & $5 \cdot 2$ & $5 \cdot 3$ & $12 \cdot 2$ & 12.7 & 12.9 & 13.5 \\
\hline 11 & 14.9 & 14.4 & $22 \cdot 1$ & $24 \cdot 0$ & $32 \cdot 1$ & 36.9 & 5.8 & 5.8 & 13.8 & 13.8 & 13.1 & $\begin{array}{l}13.5 \\
12.8\end{array}$ \\
\hline 12 & $11 \cdot 0$ & $11 \cdot 3$ & 23.0 & $22 \cdot 3$ & $29 \cdot 2$ & $29 \cdot 5$ & $4 \cdot 6$ & $\begin{array}{l}3.0 \\
4.4\end{array}$ & 14.2 & 14.4 & 13.7 & $\begin{array}{l}12.8 \\
13.5\end{array}$ \\
\hline 13 & 13.9 & 12.9 & 20.6 & $21 \cdot 0$ & 46.0 & $31 \cdot 0$ & $4 \cdot 6$ & $\begin{array}{l}4.4 \\
4 \cdot 8\end{array}$ & 12.6 & 12.7 & $11 \cdot 2$ & $\begin{array}{l}13.5 \\
11.4\end{array}$ \\
\hline 14 & $13 \cdot 0$ & $11 \cdot 6$ & $27 \cdot 8$ & $22 \cdot 4$ & $47 \cdot 0$ & $32 \cdot 7$ & $5 \cdot 2$ & $\begin{array}{l}4.8 \\
5.4\end{array}$ & 13.4 & 12.7 & 12.9 & $\begin{array}{l}11 \cdot 4 \\
13 \cdot 2\end{array}$ \\
\hline 15 & 15.4 & 18.8 & 37.0 & $34 \cdot 1$ & 41.0 & - & $5 \cdot 2$ & $\begin{array}{l}5.4 \\
5.1\end{array}$ & 13.1 & 13.4 & 12.9 & $\begin{array}{l}13 \cdot 2 \\
13 \cdot 1\end{array}$ \\
\hline 16 & 18.0 & 16.4 & $21 \cdot 3$ & $22 \cdot 6$ & - & - & $4 \cdot 8$ & $\begin{array}{l}3.1 \\
4.8\end{array}$ & 13.0 & 12.7 & 13.4 & $\begin{array}{l}13 \cdot 1 \\
13 \cdot 2\end{array}$ \\
\hline 17 & $22 \cdot 1$ & 18.8 & 47.0 & $33 \cdot 3$ & $81 \cdot 0$ & 53.0 & 4.9 & $\begin{array}{l}4.8 \\
4.9\end{array}$ & 12.7 & 12.4 & 13.1 & $\begin{array}{l}13 \cdot 2 \\
13 \cdot 2\end{array}$ \\
\hline 18 & $21 \cdot 3$ & $20 \cdot 8$ & 39.8 & $24 \cdot 7$ & - & - & 5.6 & $\begin{array}{l}4.9 \\
5.5\end{array}$ & 12.8 & 12.7 & 14.2 & $\begin{array}{l}13 \cdot 2 \\
14 \cdot 0\end{array}$ \\
\hline 19 & 23.8 & $22 \cdot 2$ & $41 \cdot 3$ & 36.8 & 83.5 & - & 4.9 & $\begin{array}{l}5 \cdot 5 \\
4.8\end{array}$ & $\begin{array}{r}12.8 \\
12.9\end{array}$ & $\begin{array}{l}12.1 \\
12.8\end{array}$ & 14.8 & 14.0 \\
\hline & $25 \cdot 5$ & 19.0 & $53 \cdot 2$ & $40 \cdot 2$ & $71 \cdot 0$ & 一 & 6.0 & $\begin{array}{l}4 \cdot 8 \\
6 \cdot 0\end{array}$ & $\begin{array}{l}12 \cdot 9 \\
14 \cdot 8\end{array}$ & $\begin{array}{l}12 \cdot 8 \\
14.9\end{array}$ & $\begin{array}{l}14 \cdot 8 \\
14 \cdot 4\end{array}$ & $15 \cdot 2$ \\
\hline Mean (SD) & & & & & & & $5 \cdot 2$ & $6 \cdot 0$ & $\begin{array}{l}14.8 \\
13.3\end{array}$ & 3) $14 \cdot 9$ & $\begin{array}{l}14.4 \\
13.5\end{array}$ & $15 \cdot 2$ \\
\hline Normal & \multirow{3}{*}{\multicolumn{2}{|c|}{$\begin{array}{l}11.6(1.17) \\
13.9\end{array}$}} & \multirow{3}{*}{\multicolumn{2}{|c|}{$\begin{array}{l}20 \cdot 6(1 \cdot 21) \\
23 \cdot 0\end{array}$}} & & & \multirow{3}{*}{\multicolumn{2}{|c|}{$\begin{array}{l}5 \cdot 3(0 \cdot 42) \\
6 \cdot 1\end{array}$}} & & & & \\
\hline Mean (SD) & & & & & \multirow{2}{*}{\multicolumn{2}{|c|}{$\begin{array}{l}27 \cdot 4(1 \cdot 56) \\
30.5\end{array}$}} & & & \multirow{2}{*}{\multicolumn{2}{|c|}{$\begin{array}{l}13.0(0.96) \\
14.9\end{array}$}} & \multirow{2}{*}{\multicolumn{2}{|c|}{$\begin{array}{l}12 \cdot 3(1 \cdot 20) \\
14 \cdot 7\end{array}$}} \\
\hline Mean +2 SD & & & & & & & & & & & & \\
\hline
\end{tabular}

Key: $\mathbf{B B}=$ Biceps brachii, $\mathbf{A P B}=$ Thenar eminence, $\mathrm{TA}=$ tibialis anterior.

$\mathrm{Pt}$. No. = Patient number, - absent response.

of the motor pathways were assessed by transcutaneous magnetic stimulation over the lower cervical (approximately $\mathrm{C} 5 / 6$ ) and lower lumbar (approximately L4/5) vertebral spines whilst recording from upper and lower limb muscles respectively (fig 1). As with cortical stimulation, slight adjustments of the stimulating coil were sometimes required to obtain the shortest latency and at least six recordings were made from each site. The latencies for upper limb muscles in the control subjects were similar to those obtained with electrical stimuli and described previously. ${ }^{5}$

Subtraction of the latency following cervical or lumbar spinal stimulation from that following cortical stimulation gave a measure of the central motor conduction time (CMCT) for each muscle. This measure represents the sum of conduction time in the descending central motor pathways, the activation time for cells in the motor neuron pool and the conduction time along the nerve roots. For cortical and cervical stimulation, subjects remained semi-recumbent on a couch and for lumbar stimulation they lay in the left lateral position.

All muscle responses were recorded using standard EMG amplifiers, mounted in a Medelec MS6 EMG apparatus with a bandpass of $3.2 \mathrm{~Hz}-3.2 \mathrm{kHz}$. Latencies were measured from paper printouts. All investigations were performed in a warm room and the experimental procedure followed was identical for both control and patient groups. The electrophysiological studies and the associated clinical examination were carried out independently by the same investigators on each occasion. Statistical analysis of results was carried out using Spearman's rank correlation and Student's $t$ tests.

\section{Results}

Magnetic. stimulation was well tolerated by all patients and control subjects. No immediate or delayed unwanted effects were observed and no patient had a relapse during at least 8 months followup. Control subjects who had previously experienced electrical stimulation ${ }^{5}$ invariably preferred magnetic stimulation. Unlike electrical stimuli, magnetic stimulation over the cervical spine failed to excite descending motor pathways in the cord of normal control subjects.

Repeatable motor responses to magnetic cortical stimulation were easily obtained from the upper limb muscles in all 20 patients with multiple sclerosis (fig 1), and responses were obtained in 33 of the 40 tibialis anterior muscles studied in the lower limbs. The seven absent responses were noted in five of the patients (tables 1 and 2) with the most marked disability (Kurtzke Scale 5 and 6). Evidence for delayed central motor conduction was found in 14 of the 20 patients studied (tables 1 and 2). Waveforms with increased latency tended to be of low amplitude and abnormally dispersed. However, this dispersion could not be easily quantified since consecutive responses showed great variability in morphology and the exact end point of individual waveforms was difficult to 
distinguish from baseline noise associated with weak voluntary contraction of the muscle under examination.

Peripheral conduction times for arm muscles (cervical spine stimulation) in multiple sclerosis patients showed no significant difference from control data ( $p>0 \cdot 1$, unpaired Student's $t$ test). Peripheral conduction times for leg muscles (lumbar spine stimulation) showed a small but significant increase over those of normal control subjects ( $p<0.001$, unpaired Student's $t$ test).

\section{CLINICO-ELECTROPHYSIOLOGICAL}

\section{CORRELATIONS}

Strength In all except two of the 80 muscles examined in the upper limbs, maximal isometric strength was normal. However, the CMCT for 40 of these 80 muscles was abnormally increased (fig 2 ). In Case 2 , although the CMCTs were within the normal range for the thenar muscles, there was abnormal right: left asymmetry (table 1). In this patient there was normal strength and deep tendon reflexes and the plantar responses were flexor. Abnormal right: left asymmetry in the presence of normal strength was also found in the biceps muscles in case 14. This patient had brisk reflexes and clinical and electrophysiological evidence of widespread disease of central motor pathways (tables 1 and 2).

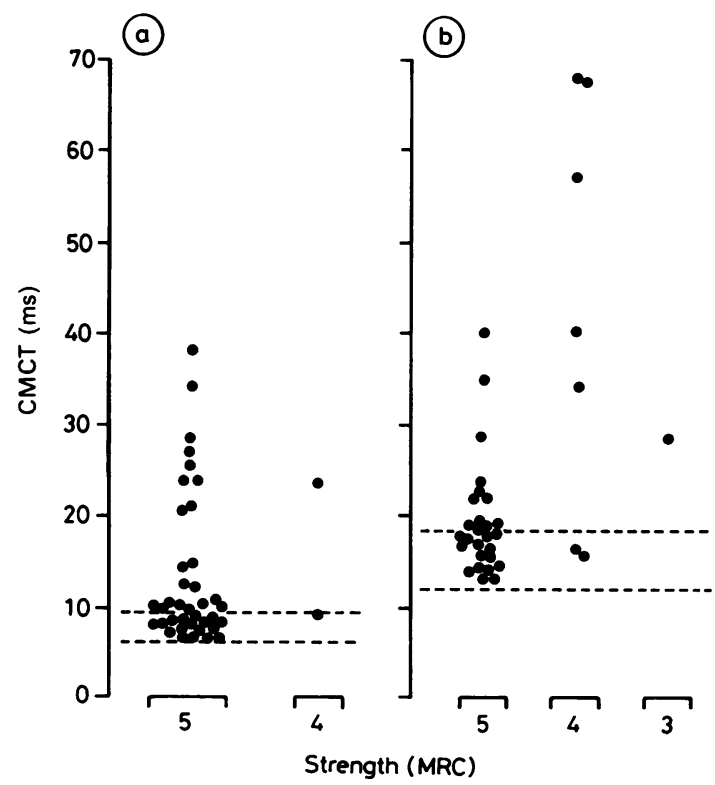

Fig 2 Relationship of CMCT to strength. The dashed lines indicate normal limits (mean $\pm 2 S D$ ). (A) Thenar muscles $(A P B)$. Half of the muscles with normal strength had increased CMCTs. (B) Tibialis anterior muscles.
In the lower limbs, weakness was more frequently encountered (fig 2) and, in all except Case 12, this was always associated with increase in CMCT for the muscle examined. As in the upper limb, a large proportion of the TA muscles with normal strength had increased CMCTs (fig 2). Motor responses to cortical stimulation could not usually be elicited in leg muscles when the strength was less than MRC Grade 4 (Cases 16, 18, 19).

Upper motor neuron signs Increased CMCTs for tibialis anterior muscles were almost invariably associated with extensor plantar responses (fig 3). In one patient (Case 10) bilateral extensor plantar responses were associated with normal CMCTs, and in Case 4 an increased CMCT ( $>4$ SD above the control mean) to one TA muscle was associated with a flexor response. Increased CMCTs were also associated with increased ankle jerks but the degree of abnormality

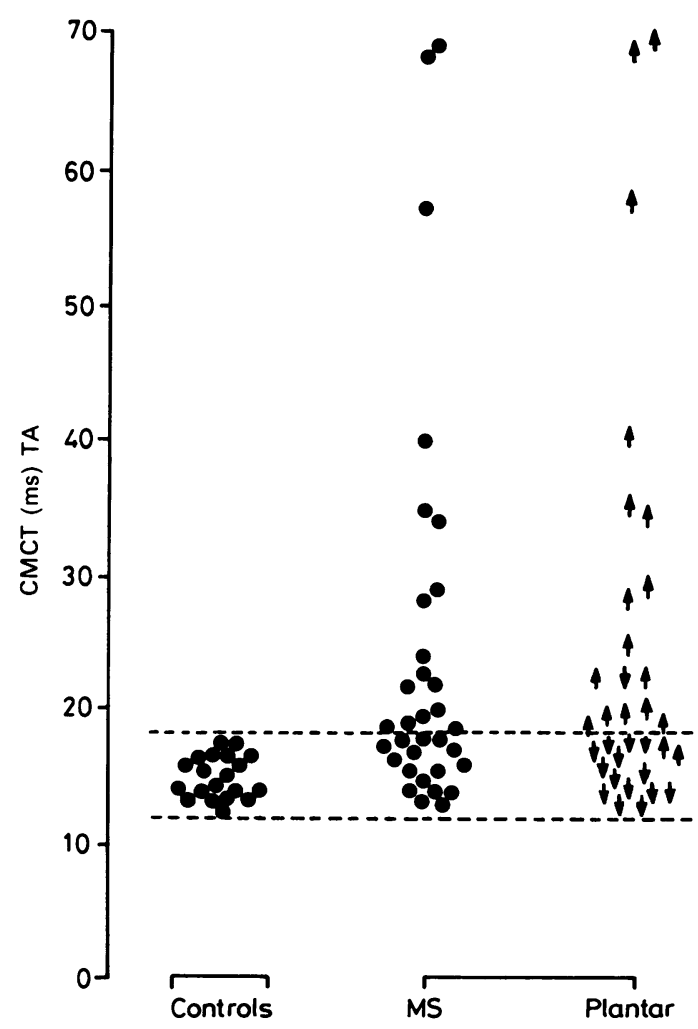

Fig 3 CMCT values for TA muscles in multiple sclerosis patients. These are plotted with the equivalent plantar response in each case shown to the right ( $\uparrow$ extensor $\downarrow$ flexor). CMCTs for control subjects are plotted on the left and the normal limits (mean $\pm 2 S D$ ) are indicated by dashed lines. There is a close relationship between increased CMCT for this muscle and an extensor plantar response. 


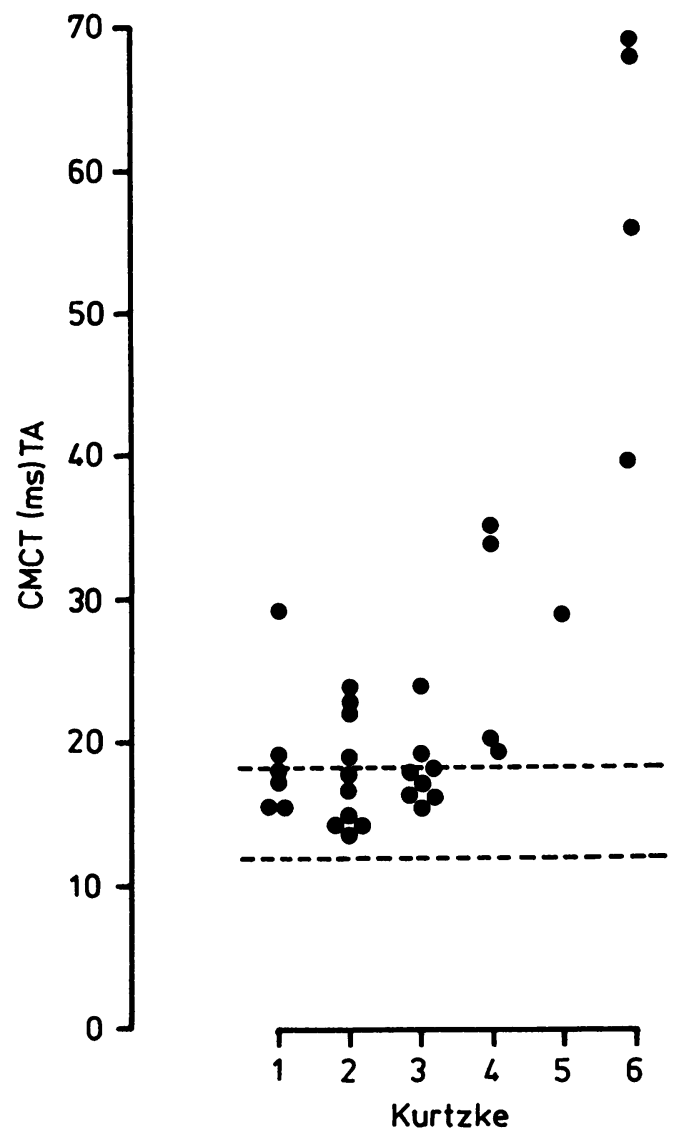

Fig 4 CMCTs for TA muscles compared with Kurtzke Disability Status Scale. Increasingly severe disability is correlated with increased CMCTs $(p<0.005)$ in ambulant patients (Kurtzke Scale $\leqslant 6$ ). Absent responses were only encountered in patients with disability of grade 5 or 6.

was not directly related to the clinical grading. (However, increased knee jerks were present in all except Cases 3 and 12). Asymmetry of the electrophysiological findings in the presence of symmetrical clinical signs, was a prominent feature in some patients (Cases 1, 13, 14, 15, 17, 19, 20). Case 4 showed symmetrical CMCTs although the right plantar response was extensor. Case 1 , with asymmetrical responses showed minimal clinical disability (Kurtzke Scale 1) with normal strength although both plantar responses were extensor. In the upper limb muscles the association of prolonged CMCT's with increased reflexes was less definite.

Functional Motor Disability The degree of electrophysiological abnormality in the lower limb muscles was closely correlated with disability in both the Kurtzke Disability Status Scale (Spearman's rank correlation coefficient $=0.603, p<0.005$; fig 4) and the Ambulatory Index (table 1).

Disease Duration There was no relation between the severity of the electrophysiological findings and duration of the disease. No attempt was made to relate the number of relapses to the electrophysiological data because retrospective verification of relapses was not felt to be sufficiently accurate.

\section{Discussion}

Transcutaneous magnetic stimulation of motor pathways in the brain and peripheral nervous system is more effective and better tolerated than electrical stimulation. We have not observed unwanted effects associated with this technique either immediately or during 8 months follow-up. None of our patients with multiple sclerosis had a relapse during this period. The electromagnetic stimulator ${ }^{6}$ is designed to deliver stimuli at no more than $0.3 \mathrm{~Hz}$; stimuli applied to the brain at this frequency have not been associated with "kindling" or epileptogenic effects. ${ }^{12}$ The energy dissipated in the brain during electromagnetic stimulation is comparable to that associated with MRI. ${ }^{13}$

CMCTs obtained with magnetic stimulation of the brain are approximately 1 to $2 \mathrm{~ms}$ longer than those recorded following transcutaneous electrical stimulation. ${ }^{11}$ This difference probably indicates that the former method preferentially excites descending motor pathways indirectly, through interneurons, but the precise cortical structures stimulated are at present unknown. ${ }^{14}$

In patients with degenerative diseases, for example motor neuron disease, ${ }^{5}$ and in multiple sclerosis, ${ }^{2}$ electrical stimulation may fail to excite central motor pathways. Since magnetic stimuli are not attenuated by body tissues ${ }^{6}{ }^{13}$ failure to achieve effective brain stimulation is less likely to occur with this alternative form of stimulation. In the present study we obtained responses from all the 80 arm muscles studied in our patients with multiple sclerosis, whereas Cowan et $\mathrm{al}^{2}$ using electrical stimulation, failed to elicit adequate responses from upper limb muscles to cortical stimulation in three of the 25 muscles they studied, even though most of their patients had little or no disability. Similarly, responses in leg muscles are generally easier to obtain with magnetic than with electrical stimulation of the cortex in patients with lesions of the central motor pathways. ${ }^{5}$ We elicited responses with magnetic stimulation in 33 of the 40 tibialis anterior muscles in our 20 patients with multiple sclerosis. The seven absent responses occurred in those patients with the most severe disability-Kurtzke Scale grades 5 and 6 only (table 1). The increased efficacy of magnetic brain stimuli in disease might be partly explained by the 
generation of descending volleys whose discharge patterns are more effective in raising the excitability of alpha motor neurons to firing threshold, thus eliciting a response in target muscles. In contrast to electrical stimulation techniques, ${ }^{3}{ }^{5}$ descending motor pathways within the spinal cord, however, cannot be directly stimulated and this precludes separate evaluation of cord function.

In our patients with multiple sclerosis an increase in CMCT for leg muscles correlated with the clinical features of upper motor neuron lesions and with the degree of functional motor disability. All the patients were ambulant and abnormalities of motor conduction were revealed even in patients with mild functional disability (Kurtzke Scale 1-3) and normal strength. Although CMCTs were almost invariably increased for weak muscles, markedly increased CMCTs were found in some patients in whom strength was normal. In this latter group clinical features of upper motor neuron involvement were usually present. The magnitude of slowing of central motor conduction varied with disability, and reached a threefold change at its most severe. Similar degrees of slowing of central conduction have been recorded in experimental demyelination in the cat spinal cord $^{1516}$ and it would be reasonable to conclude that most of the impairment we have observed in our patients with multiple sclerosis is related to demyelination. No slowing of conduction was found in the lower motor neuron segment of the motor pathway in the upper limbs. In the lower limbs there was a slight but significant increase in peripheral conduction times which suggests that a minor disturbance of peripheral motor conduction occurs in some patients.

Abnormal muscle responses following stimulation of motor pathways in the brain usually showed increased dispersion but this could not be reliably quantified because of the inherent variability in morphology of these responses to successive stimuli. This variability is a characteristic finding of motor responses elicited by cortical stimulation even in normal subjects. ${ }^{2} 5$ Increased dispersion might be related to several factors including changes in the arrival times of nerve volleys at the anterior horn cell pool of a muscle and changes in the excitability of anterior horn cells when their central connections are abnormal. Both slowing of central motor conduction and dispersion of the muscle responses may be important in understanding fatiguability in patients with multiple sclerosis. Slowing of central motor conduction is not, however, specific for multiple sclerosis; it has also been described in radiation myelitis $^{3}$ and motor neuron disease ${ }^{5}$ and in association with vascular and compressive lesions. ${ }^{17} \mathrm{CMCT}$ measurements are thought to mainly reflect conduction in the fast-conducting corticospinal tracts. ${ }^{2-5}$
However, in advanced disease of the pyramidal tracts, other descending pathways such as the cortico-rubrospinal tracts ${ }^{18}$ may contribute the fastest conducting fibres.

We have not attempted to compare these abnormal motor responses with the results of sensory evoked potential studies. The latter are concerned exclusively with conduction in sensory pathways which are anatomically separated from central motor tracts and would therefore not be expected to correlate with CMCTs. However there are important advantages associated with CMCT measurements. In particular, they specifically sample motor pathways and generally involve large, easily recordable muscle responses to single stimuli, even in the presence of disease. The latter characteristic avoids the need for averaging multiple responses which is required for sensory evoked potential studies. CMCT measurements are thus less time consuming and technically less demanding. They directly assess central motor pathways and provide data which can be correlated both with functional disability and with clinical signs of central motor disorders. Subclinical abnormalities of central motor conduction can also be easily demonstrated. Central motor conduction time measurements using magnetic stimulation of the CNS should therefore prove valuable in the diagnosis and management of patients with multiple sclerosis and other disorders affecting central motor pathways.

This work was supported by Action for Research into Multiple Sclerosis and was presented in part at the inaugural meeting of The American Academy of Clinical Neurophysiology, Boston, Mass., June 1986.

\section{References}

1 Merton PA, Morton HB. Stimulation of the cerebral cortex in the intact human subject. Nature 1980;285: 227.

2 Cowan JMA, Rothwell JC, Dick JPR, Thompson PD, Day BL, Marsden CD. Abnormalities in central motor pathway conduction in multiple sclerosis. Lancet 1984; ii:304-7.

3 Snooks SJ, Swash M. Motor conduction velocity in the human spinal cord: Slowed conduction in multiple sclerosis and radiation myelopathy. $J$ Neurol Neurosurg Psychiatry 1985;48:1135-9.

4 Mills KR, Murray NMF. Corticospinal tract conduction time in multiple sclerosis. Ann Neurol 1985;18:601-5.

5 Ingram DA, Swash M. Central motor conduction is abnormal in motor neuron disease. J Neurol Neurosurg Psychiatry 1987;50:159-66.

6 Barker AT, Jalinous R, Freeston IL. Non-invasive magnetic stimulation of human motor cortex. Lancet 1985;i:1106-7.

7 Poser CM, Paty DW, Scheinberg L, et al. New diagnostic criteria for multiple sclerosis: guidelines for research 
protocols. Ann Neurol 1983;13:227-31.

8 McDonald WI, Halliday M. Diagnosis and classification of multiple sclerosis. Br Med Bull 1977;33:4-8.

9 Kurtzke JF. Neurologic impairment in multiple sclerosis and the Disability Status Scale. Acta Neurol Scand 1970;46:493-512.

10 Hauser SL, Dawson DM, Lehrich JR, et al. Intensive immunosuppression in progressive multiple sclerosis. $N$ Engl J Med 1983;308:173-180.

11 Hess CW, Mills KR, Murray NMR. Magnetic stimulation of the human brain: The effects of voluntary muscle activity. J Physiol (Lond) 1986;378:37P.

12 Goddard GV, McIntyre DC, Leech CK. A permanent change in brain function resulting from daily electrical stimulation. Exp Neurol 1969;25:295-330.

13 Barker AT, Jalinous R, Freeston IL, Jarratt JA. Clinical evaluation of conduction time measurements in central motor pathways using magnetic stimulation of human brain. Lancet 1986;i:1325-6.

14 Young RR, Cracco RQ. Clinical neurophysiology of conduction in central motor pathways. Ann Neurol 1985;18:606-9.

15 Rasminsky $M$, Sears TA. Internodal conduction in undissected demyelinated nerve fibres. $J$ Physiol (Lond) 1972;227:323-50.

16 McDonald WI, Sears TA. The effects of experimental demyelination on conduction in the central nervous system. Brain 1970;93:585-98.

17 Ingram DA. Central motor conduction in neurological disorders. In: Rossini PM, Marsden CD (eds) Non-invasive Stimulation of Brain and Spinal Cord: Fundamentals and Clinical Application. New York: Liss, 1988 (In Press).

18 Brodal A. Neurological Anatomy in Relation to Clinical Medicine. 3rd ed. Oxford: Oxford University Press, 1981. 